\title{
Technical Sensibility: On sexual and technical performance
}

\author{
Ana María Guzmán Olmos \\ Independent Researcher \\ Berlin, Germany \\ sositap@gmail.com
}

\begin{abstract}
This paper peers into sexual practices articulated between human bodies and digital connected devices in order to produce a critical perspective on techno-sexual practices. Are sexual pleasure production technologies exhausted by their marketed functionalities? By considering Gilbert Simondon's technicity concept and the genesis of technical objects, I'll answer this question negatively. My hypothesis is that technologies for sexual pleasure production exceed the functionalities attributed by their marketing because they are part of a broader process of technological becoming. I'll state that sex toys, marketed as digital or smart technologies, belong to what I will later call technical sensibility, which is at the core of a libidinal approach to processes of technological production.
\end{abstract}

Sex Toys. Technicity. Pleasure. Techno-Sexuality. Cyberfeminism.

\section{INTRODUCTION}

In 1991 the Australian cyberfeminist group VNS Matrix called our attention to the relationships between female bodies, pleasure and their pornographic articulation within cybernetic spaces. In this paper, I will approach those relations by asking what their contemporary conditions of production are, and how they relate to processes of technological becoming. To this aim, l'll specifically peer into sexual practices articulated between human bodies and digitally connected devices; I will look into the marketing and functionalities of sex toys.

VNS Matrix's Cyberfeminist Manifesto was framed within a political resistance discourse and intended to imagine the digital space as a center for reclaiming female agency, but what does the line to the matrix look like today? How exactly does the clitoris get connected to the web? How are we to understand what happens in the sexual encounters between human bodies and technological devices under the current conditions of biodigital capitalism? And how do those connections relate to the ways in which bodies and sex are signified?

A considerable number of products within the sex toys industry have recently been advertised as smart sex toys, or digital and Al Technologies. The capitalization of sexual pleasure transformed and exchanged as data would be an issue to discuss within the context of reframing the question of digital female agency, but, in order to contextualize that question for future examinations, this text has a more modest approach, and it starts by simply looking closer to the kind of functionalities offered by digitally connected sexual technologies.

Are sexual pleasure production technologies exhausted by the functionalities produced within their marketing? By considering Gilbert Simondon's technicity concept and the genesis of technical objects, I'll answer this question negatively. My hypothesis is that technologies for sexual pleasure production exceed the functionalities attributed by their marketing because they are part of a broader process of technological becoming. I'll state that sex toys, marketed as digital or smart technologies, belong to what I will later call technical sensibility, which is at the core of a libidinal approach to processes of technological production. My aim is to produce a framework in which a critical perspective on techno-sexual practices can help to explain the role that sexual technologies play within broader processes of technological becoming.

\section{MIMETIC FUNCTIONALITY}

Let's take a look at the functionalities offered by the marketing strategies of sex toys. Before we proceed, we should, however, consider that this is by no means an analysis of discourse; the kind of functionalities we are examining are not only attributed linguistically, but framed within a variety of economic practices, epistemic relations, and material formations that can't be reduced to their linguistic formulation. And it is precisely for this reason that they will help us to understand what kind of economy of bodies is linked to this market.

The first aspect we should pay attention to, is the 
mimetic functionality orchestrated by means of the features and qualities of the sex toy. So, for example, according to the website of the "HUM“ smart vibrator:

Hum is a smart vibrator in the ultimate sense of the word (...). Unlike most vibrators, which typically only let you cycle through a few set levels of speeds and vibration patterns, Hum responds to its user's movements to provide a unique sexual experience that mimics what it's like to be with an actual human partner (HUM Website, retrieved 15 June 2018).

The smart vibrator becomes, in this way, an enabler for a mimic mechanism, in which the archetype is the sexual practice performed with a human partner. This mechanism indicates a model to be reproduced, but also a hierarchy in which the sexual relation with a human is the one to be desired and the vibrator becomes a substitute in the face of a lack of such a partner.

The second aspect to highlight is the qualities these devices promise to deliver in their sexual encounters. For example, if we stay with HUM, the Al vibrator, we observe that it offers a variety of reactions, which are supposed to work together in order to produce a unique orgasm:

HUM is attentive, smart, and intuitive. HUM feels your touch and motion, and the computer inside tells HUM how to respond. Because it feels you, HUM responds intuitively, and is as easy to use as any other vibrator ... just turn it on, and it's ready (HUM Website, retrieved 15 June 2018).

The singular experience offered by these devices goes in hand with its mimetic aim, as human sex is implicitly conceptualized as unique and particular. According to this functionality, human sex is a process in which the relation between the bodies involved in the act respond in a manner that is particular to singular encounters.

The relation between the singularity and the mimesis offered by the smart sex toy is particularly compelling to look at in the context of its definition of human sex, and the role of technology within it. On the one hand we are told that technology should mimic human sex, on the other hand, this kind of sex is defined by its uniqueness. However, the promise of the smart vibrator is the reproduction of the uniqueness itself. Even though the mimetic functionality of sex toys can easily be seen skeptically, as it takes human sex as its model, what is interesting here is the shift that occurs by its mixture with the process of singularity. Not only sex becomes reproducible, but uniqueness itself can be technically produced. This mixture of functionalities is a shift from an ontological hierarchy in which that what is lacking is above its substitute. Sex, human or technological, remains singular, but the uniqueness attributed to sexual processes stops being impossible to reproduce. This doesn't mean to say that human sex stops being the model, but that the conditions for its reproduction are different because now include the possibility of the reproduction of the "uniqueness" itself.

And we arrive to a third functionality offered by these kinds of devices. We encounter here the Stamina Training Unit, which traditionally, as its name tells us, should provide users with a tool to enhance sexual performance:

Practice makes perfect, especially in the bedroom. The Stamina Training Unit was specifically designed to replicate the intense sensations of intercourse, which can help users increase sexual stamina, improve performance and techniques, and heighten and intensify orgasms (Fleshlight Website, retrieved 15 June 2018).

Within this context we should pay special attention to the functionality of the Vstroker: STU, one of the Stamina Training Units offered by the website fleshlight.eu:

Attached to a Fleshlight, the VStroker monitors the speed of your strokes. Every penetration of your Fleshlight is wirelessly transmitted to your Mac or PC and simulated within the Vstroker enabled content (Fleshlight Website, retrieved 15 June 2018).

We can recapitulate the three functionalities that digitally connected sexual technologies should provide according to the sex toys market as follows:
(1) mimesis
(2) singularity
(3) enhancement

It is important to be aware that these attributes are not all the functionalities we can find within this industry; they could be broadly expanded by observing some other cases. Nevertheless, I'm not framing these functionalities as part of a finite list which entirety would mean a universally valid definition of what (digital) sex toys are, but as representative of a general characteristic of the way in which this market approaches to sex and technology.

The three above listed functionalities take part in the shaping of a semio-technical ${ }^{1}$ core, out of which both sexual pleasure and technology are formed. By orchestrating these attributes, sex toys marketing defines how sexual practices should function, which of those practices enable pleasure (for example, those involving the encounter with an actual human partner), and how to perform them in order to produce sexual pleasure in the human body; and, at the same time, they determine the role that technology should have within its sexual encounters with human bodies. 
At this point we should not overlook that, by being discursively actualized in the kind o f advertisements we just presented, and crystalized in the shape, material and features included within concrete sex toys, a deontology of techno-sexual practices becomes an ontology. So, our critical eye should be directed to the way in which this semio- technical core gets universalized, and those attributes take the form of an essentialized economy of sexual practices, pleasure, and technology.

Could such a critique lead to possibilities of nonhuman sexual practices? What would that kind of pleasure production mean for the social formation of sexuality? What would the consequences be for our conceptualization of the role of technology in sexual processes? And, would it have an effect on our understanding of technology itself? In this context, we should also consider the kind of framework that tagging sex toys as Al or digital technologies offers within that market. What makes a computational approach to sexuality attractive? What kind of assumptions would be responsible for the framing of computational sexuality as something to be desired? But we will peer into these questions latter.

\section{ECONOMY OF BODIES}

In her book Körper 2.0, the media theorist Karin Harrasser has already criticized the discourses on technology that frame it as mimetic, singular, and as enhancement tools. Specifically, within the context of prostheses designed for people with disabilities, technology gets advertised as a singular product, as it is created for a specific individual with particular physiol o g i c a I characteristics (Harrasser 2013). According to Harrasser, protheses are individually crafted, but can't be described as singular because they are produced in consonance with standardized measures belonging to mass production regulations. By following such regulations, the production of prostheses reproduces the archetypical forms of what is understood as a regular or generic body, these regulations are created as enablers of an image of such ideas of the "normal" body (Harrasser 2013). Technology functions, according to these discourses, as an extension of human capabilities and potentialities, a move by which a universal definition of what it means to be human is always being played in the background, which means: no singular experience is taking place.

We can see quite easily how this discourse on technology as mimetic, singular and as enhancement tools impacts sexual technologies. First of all, as stated above, they appear as copies of a sexual experience with a human partner, they are ordered towards a model, and it is the human sexual experience the one playing such a role. This is, by the way, an important difference of these devices when compared to non-smart devices ${ }^{2}$, because it is not the shape or look of the object that is central to the mimesis, but the experience it provides; the experience is the model. Second, they offer a singular experience of what is actually the enactment of the functionalities available in the device, or what James Ash has called their allopoietic and homeostatic structure (Ash 2018). And third, they offer their functions in order to increase what is allegedly the potentialities of bodies performed in sex.

By following these descriptions, we get a picture of their conception of sexual performance: there is in sex a potential which can be improved, either as an increase of its experience - a qualitative improvement - or an increase of their bodily potentials - a quantitative improvement which at the end of the day, get translated into a qualitative improvement as well. In this way, the extension of human sexual potential belongs to a bio-economy affirming both:

(1) the capitalization of sexual experiences and (2) an understanding of technology as extension of human potential.

Of course, both elements are dependent each one on the other, as the extension of human potential is always already based on the assumption that there is - and should be - a surplus in human sexual experience and this can be reached and captured by using technologies.

As we can see, there is in these discourses by no means a prohibition of pleasure, quite the contrary: what is being marketed is their production of an increase in pleasure. ${ }^{3}$ This is precisely one of the main effects of framing sexuality as a digital and Al Technology, they offer an increase in the human sexual experience. But what role does this affirmation of pleasure play within a wider economy of bodies?

Tiziana Terranova and Luciana Parisi have framed the change from disciplinary and control conceptions of the body as a shift from the thermodynamical to the turbulent body (Terranova \& Parisi 2000). While disciplinary societies where concerned with the administration of solid bodies - performed as incarceration or other strategies for confinement of bodies as singular entities - control societies are structured around the management of fluids and its turbulence (Terranova \& Parisi 2000).

For Terranova and Parisi, the conception of bodies as solid entities its compatible with their understanding as thermodynamic organisms. This means that their functions are all aligned with a hierarchical order that 
commands what specific role each one of the organs has in order to manage the energy getting in and out of the system. This mechanism should serve for avoiding disorder or the absolute disintegration of the body, or in their words:

The thermodynamics of the disciplined body moves beyond the reversible time of Newtonian causality towards irreversibility and stability. The thermodynamic organism survives in equilibrium, which it maintains by engulfing energy from Outside its semi-closed cycle. This energy needs, then, to be discharged because its irreversible increase (entropy) threatens to destroy the organism. The organism must ward of $f d e a t h$ constantly by charging and releasing the energy thus accumulated: nothing must be dissipated, everything must be used up and discharged once it has exhausted its function (Terranova \& Parisi 2000).

Within this framework, if we locate sexual technologies within the logic of entropic bodies, we find quite quickly that sexual performance should function as a charge-discharge mechanism of the organism, where orgasm takes the form of a release. Sexual energy would be an excess within the body that should find a way out, otherwise it risks the destruction of the organism. ${ }^{4}$ The sexual device would be an extension of the human body at the service of a charge-discharge mechanism responsible for maintaining the system in equilibrium ${ }^{5}$. But, are these devices serving such a system?

On the one hand, we could consider the above presented functionalities as a mechanism working in order to, at the same time produce and extract the surplus of human potential affirmed as part of the conception of sexual and technological performance we saw before. On the other hand, we need to consider that this extraction of potential does not take place as an administration of solid bodies since no subjection or confinement is taking place, but quite the contrary, it is an extension of the potential marketed as an increase in pleasure what is advertised; it is a production and management of pleasure what we observe.

In order to conceptualize the techno-sexualities operating today and its link to the bio-economy of its surplus extraction we need to ask some more questions. Are sex toys, as marketed today, compatible with a disciplinary conception of bodies? Or do they rather belong to what Parisi and Terranova have called the turbulent body and its systems managing fluid capital? Or neither of them, and they escape both characterizations of the body and their economies?

\section{TECHNICAL OBJECTS}

As we are at this point still thinking of sex toys according to the marketed functionalities, it becomes relevant to remember here the question we posited at the beginning of these reflections: are the functionalities of sexual devices exhausted within the marketing framework? In order to address this question, let us consider these devices in relation to their particularity as technical objects. This, of course doesn't mean to ignore the definition of sexual performance we observed in relation to the functionalities listed before, but quite the contrary, it means to look at them critically from a technical perspective.

So, for the rest of this text, I will very briefly approach the concept of technicity developed by the french philosopher Gilbert Simondon. The aim is to reframe the previously mentioned question on the functionalities of sexual technological objects, and how those functionalities could be outlined within a broader process of technological becoming. By considering technological becoming as part of the context for the understanding of sexual technologies, I'm aiming to create a framework for the understanding of techno- sexualities that goes beyond the marketing of sex toys, but can still look critically at it. This scheme should offer the conditions for the thought of a critical perspective on sexual practices, as it is not centered on what has been crystallized in the features of the devices and the discourse surrounding them, but focused on their technological condition as such.

In a posthumous essay entitled Technical Mentality Simondon points to the existence of a technical schema of thought, which he calls precisely technical mentality, a schema responsible for technical invention (Simondon 2017). The technical mentality should be understood in relation to another central concept within Simondon's thought: technicity. Technical objects get individuated by means of the degree of technicity they have (Hui 2016), which means the degree of stability they obtain in relation to their associated milieu, that is, in the relation with the environment in which they evolve (Hörl 2013).

Simondon uses the concept of technicity to describe a systematic incompatibility of technical systems with themselves, one produced by the necessary separation of individuals out of a field full of potential, a relation that he describes with the concepts of form and background - categories he borrows from the Gestalt theory - and the fundamental unity of the field of potential (Simondon 1980). This incompatibility gives place to the formation of individuated technical objects. Nevertheless, the appearance of an individual can't 
mean the absolute resolution of the incompatibility since the tension itself is the condition of possibility of any individuation at all (Simondon 2017). So, in order for further individuations to take place, the incompatibility needs to remain as active force in the background, or in Simondon words:

(T)he discovery of a structure is indeed at the very least a provisional resolution of incompatibilities, but it is not the destruction of potentials; the system continues to live and evolve; it is not degraded by the emergence of structure; it remains under tension and capable of modifying itself (Simondon 1980).

This fundamental tension means for Simondon a specific temporality of technical individualization, since it is only because the conditions of appearance of specific technical objects are not caused either by the environment in which they emerge, or the material elements of the object itself, but by the resolution of a disparity at the moment of their encounter, that individualization is not caused by conditions of the past, but of the future (Massumi 2009). The conditions for the individualization of the object would only be there once the object is constituted, once a productive disparity takes place, although the disparity already plays a role in the present development of the object (Simondon 1980).

At this juncture the technical mentality gets involved in the process. Invention is an intervention within the temporality leading technical processes of becoming (Simondon 1980). Technical mentality is the force coming from the future which enables individualization (Simondon 1980); it enables the dissolution of incompatibilities:

\begin{abstract}
The participational relationship connecting forms to their background is a relationship which straddles the present and brings the future to bear upon the present, that which brings the virtual to bear upon the actual. This is so because the base is a system of virtualities, of potentials, and of moving forces, whereas forms are a system of the actual. Invention is a taking into account of the system of actuality by a system of virtualities; it is the creation of a new system from these two (Simondon 1980).
\end{abstract}

Brian Massumi critically approaches a reading of Simondon's technical mentality according to which he would be assuming an "ultra-rationalized technocratic cybercontrol" (Massumi 2009), in which an abstract model of the mind of technical inventors would take place (Massumi 2009) and "the origin of the technical object (would be) purely cognitive, and entirely internal to the human thinking subject" (Massumi 2009). Instead, according to Massumi we need to take into account Simondon's proposal of the temporality involved in the process of form-giving
(Massumi 2009); because, as we just saw, it would be against Simondon's own project to propose a form fully actualized in a human mind which then only needs to pop up into matter to give shape to a technical individual. I'm following Massumi in this reading and avoiding a cognitive understanding of the technical mentality. As stated above, the technical mentality should be conceptualized as the force responsible for the resolution of disparities.

Here it is important to notice that Simondon in no way refers to sexual/pleasure relations between humans and technology. His lack of consideration of sexuality as an array of technical objects could be seen as a merely fun anecdote, after all he is not listing all of the possible technical objects existing in the world or their relation to humans, but producing an ontogenetic schematization. It is neither the concrete lack of consideration of sexual objects nor possible "ultra-rationalized" readings what should make us look critically at the technical mentality, but the way in which capital and technical production have shifted since Simondon's writings. How are we to think the ontogenesis of technical objects within the context of biodigital capitalism? The marketing of technologies for sexual pleasure production might help us understanding what kinds of forces move technical development under such conditions.

These conditions are also the one leading us to look beyond the categorization of digital and $\mathrm{Al}$ sexual devices either as disciplinary or control technologies, and their corresponding economies. James Ash has, for instance, framed this shift as a structural change within technological devices, one in which we go from technical to smart objects (Ash 2018); but it seems that a structural explanation is not enough if we are looking to understand how that shift impacts the economy surrounding the definition of what bodies, sex and technology, and its relations are. With reference to Simondon's technical mentality, I propose instead to think of the libidinal approach to sexuality and technology as a move to a technical sensibility. By this I'm pointing to the hypothesis that the process of technical becoming, specifically in the context of contemporary devices for sexual pleasure production, is not leaded by its technical requirements of evolution - the resolution of its internal disparities , but the ones constituted by its marketing: mimesis, singularity, enhancement.

What becomes urgent to understand both this approach to techno-sexuality and its role in the wider picture of the process of technical becoming is a conceptualization of the kind of forces directing the current economy of bodies. This is no small enterprise, but rethinking the conditions of technological becoming -which is the proposal of this text - would be a first step in that direction. 
In this way, Simondon's lack of consideration of techno-sexualities doesn't mean that he can't give us tools for a critical understanding of technosexuality. If we think of technicity, as the immanent tension of technical systems it is essential, in order for technical objects to exist, that technicity precedes and goes beyond the particular objective formations:

\begin{abstract}
(I)t is insufficient, for understanding technics, to start from constituted technical objects; objects appear at a certain moment, but technicity precedes them and goes beyond them; technical objects result from an objectivation of technicity; they are produced by it, but technicity does not exhaust itself in the objects and is not entirely contained within them (Simondon 2012).
\end{abstract}

So, instead of thinking of sex toys as constituted technical objects, we should be looking at them as one of the centers of the forces leading technical invention; which doesn't mean to say that all technics are potential sex toys, ${ }^{6}$ but that at the core of biodigital capitalism is the sexualization of technology leading its processes of becoming. The question we need to ask today is how has the technical mentality been replaced by a technical sensibility. This doesn't mean an opposition between cognitive and sensible processes, but to recognize that the technosomatic categories are being placed at the core of how technical production is directed.

We might still don't know how to react to the sexualization of technological production, but understanding the longer processes of technical becoming to which technical production is linked is one way to go. For instance, by the end of his book on Technical objects (1980) Simondon claims:

The technical imagination may be considered as defined by a particular sensitiveness to the technicity of elements that paves the way for the discovery of possible connections (Simondon 1980).

By concentrating ourselves on the technicity of technical objects we might find a different approach to technics that goes beyond its marketing and its libidinal forces, we might find precisely the way to the technical mentality as defined by Simondon. It is in the relation between the field of potential and the formation taking place that a critical view on the libidinal development of techno-sexuality - to technics, sex, and bodies - can be produced.

As the process of form-giving is linked to an immanent and fundamental tension between the object and its environment, between actuality and virtuality, we need to consider this tension occurring in the interactions between human bodies and sex toys as one that puts into action this fundamental tension. The essential aspect of this tension lies in the condition of its irresolution, this is why each of their interactions performs the fundamental tension, or as Massumi puts it:

Technically speaking, it is this return event of formation - and not the form - that repeats itself. It is less that a form is reproduced, than that an invention repeats itself (Massumi 2009).

From the point of view of technicity, the erotic encounters between human bodies and technological devices shape a different kind of performance than the one portrayed by their marketing strategies, precisely because we recognize that they take part in a broader process, the process of becoming of technical beings.

Sexual performance is in this line of thought less about enhancement, than it is about the reiteration of the tension between the technical object and its associated milieu. Technical becoming is taking place in each one of those erotic encounters, as it is at the core of the relation between technicity and technical invention, but we must make our way to that tension from the techno-somatic framework surrounding sexual technologies today. Hence the relevance of an approach to technology from its sexual operations and its sexualized forms.

In times of biodigital capitalism we need to rethink what technicity is, and how technology enters processes of change. Techno-sexuality is one possible approach, but many others are yet to come.

\section{REFERENCES}

Ash, J. (2018) Phase Media. Space, Time, ad the Politics of Smart Objects. Bloomsbury, New York, London

Harrasser, K. (2013) Körper 2.0. Über die technische Erweiterbarkeit des Menschen. Bielefeld, Transkript.

Hui, Y. (2016) On the existence of digital objects. University of Minnesota Press, Minneapolis; London.

Hörl, E. (2013) Die technologische Bedingung. Beiträge zur Beschreibung der technologischen Welt. Suhrkamp, Berlin.

Massumi, B. with Arne De Boever; Alex Murray and Jon Roffe (2009) "Technical Mentality" revisited: Brian Massumi on Gilbert Simondon. 
Parrhesia (7), pp. 36 - 45.

Mains, Rachel (1999) The technology of orgasm. ,Hysteria', the Vibrator and Women's Sexual Satisfaction. The John Hopkins University Press, Baltimore, London.

Lyotard, J.F. (1993) Libidinal Economy. Indiana University Press. Bloomington, Indiana.

Parisi, L. (2004) Abstract Sex. Philosophy, BioTechnology and the Mutations of Desire. Continuum, London-New York.

Preciado, B. (2002) Manifiesto Contrasexual. Pensamiento, Madrid.

Preciado, P. (2013) Testo Junkie. Sex, Drugs, and Biopolitics in the Pharmacopornographic Era. The feminist Press, New York.

Simondon, G. (1980) On the mode of existence of technical objects. Ontario: University of Western Ontario.

Simondon, G. (2012) Technical Mentality. In Arne De Boever, Alex Murray, Jon Roffe, and Ashley Woodward (eds.), Gilbert Simondon: Being and Technology. Edinburgh University Press, pp. 236.

\section{Internet Sources:}

HUM Website. https://www.dailydot.com/ debug/ hum-smart-sex-toy/ (retrieved 15 June 2018).

Fleshlight dot EU. https:// www.fleshlight.eu (retrieved 15 June 2018).

A Cyberfeminist Manifesto for the 21th Century. Net Art Anthology. https://anthology.rhizome.org/ a- cyber-feminist-manifesto-for-the-21st-century (retrieved 15 June 2018.)

Lamarre, T. (2012) Humans and Machines. Inflexions No. 5 - Milieus, Techniques, Aesthetics.

http://www.inflexions.org/n5 lamarrehtml.ht $\mathrm{ml}$ (retrieved 15 June 2018).

Parisi, L., Terranova, T. (2000) Heat-Death. Emergence And Control In Genetic Engineering And Artificial Life. ctheory.net http:// www.ctheory.net/articles.aspx?id=127 (retrieved
15 June 2018).

Simondon, G. (2017) The Genesis of Technicity. e- Flux (82) https://www.eflux.com/journal/82/133160/ the-genesis-of-technicity/ (retrieved 15 June 2018)

\section{Notes}

1 The term was coined by Paul Preciado in Testo Junkie. Sex, Drugs, and Biopolitics in the Pharmacopornographic Era. New York: The feminist Press, 2013, pp. 116 - 118.

2 For a broader analysis on Smart Objects see: James Ash: Phase Media. Space, Time, ad the Politics of Smart Objects. New York; London: Bloomsbury,2018, pp. 10.

3 An important difference in relation to other objects of this technical family, for example the electromechanical vibrator. For a wider historical and critical perspective on the electromechanical vibrator see: Rachel Mains, The technology of orgasm. "Hysteria', the Vibrator and Women's Sexual Satisfaction. Baltimore; London: The John Hopkins University Press, 1999 and Manifiesto Contrasexual. Madrid: Pensamiento, 2002.

${ }^{4}$ An interpretation which, as has been observed by Annamarie Jagose has displaced orgasm from the center of both queer theory and philosophy. Orgasmology. Luciana Parisi situates masturbation within this conceptualization of orgasm as the ultimate aim of sexual processes in Abstract Sex. Philosophy, Bio- Technology and the Mutations of Desire. London-New York: Continuum, 2004, pp.12.

${ }^{5}$ An interpretation compatible for example with the use of vibrators in the context of the biopolitics involved in the treatment of hysteria.

${ }^{6}$ Which also doesn't mean to say that they are not potentially reused for those proposes. 